\title{
Isotope Exchange and Fractionation Corrections for Extraction of Tritiated Water in Silica Gel by Freeze-Drying Techniques
}

E.B. Guthrie, N.C. Shen, B.B. Bandong

\section{September 24, 2001}

U.S. Department of Energy

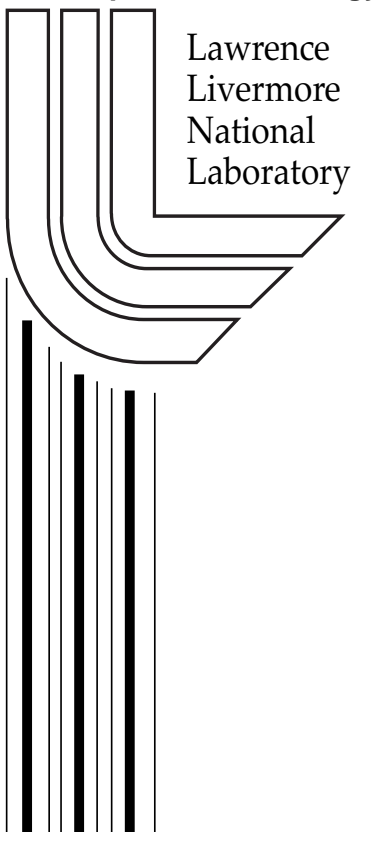




\section{DISCLAIMER}

This document was prepared as an account of work sponsored by an agency of the United States Government. Neither the United States Government nor the University of California nor any of their employees, makes any warranty, express or implied, or assumes any legal liability or responsibility for the accuracy, completeness, or usefulness of any information, apparatus, product, or process disclosed, or represents that its use would not infringe privately owned rights. Reference herein to any specific commercial product, process, or service by trade name, trademark, manufacturer, or otherwise, does not necessarily constitute or imply its endorsement, recommendation, or favoring by the United States Government or the University of California. The views and opinions of authors expressed herein do not necessarily state or reflect those of the United States Government or the University of California, and shall not be used for advertising or product endorsement purposes.

This work was performed under the auspices of the U. S. Department of Energy by the University of California, Lawrence Livermore National Laboratory under Contract No. W-7405-Eng-48.

This report has been reproduced directly from the best available copy.

Available electronically at http://www.doc.gov/bridge

Available for a processing fee to U.S. Department of Energy

And its contractors in paper from

U.S. Department of Energy

Office of Scientific and Technical Information

P.O. Box 62

Oak Ridge, TN 37831-0062

Telephone: (865) 576-8401

Facsimile: (865) 576-5728

E-mail: reports@adonis.osti.gov

Available for sale to the public from

U.S. Department of Commerce

National Technical Information Service

5285 Port Royal Road

Springfield, VA 22161

Telephone: (800) 553-6847

Facsimile: (703) 605-6900

E-mail: orders@ntis.fedworld.gov

Online ordering: http:/ / www.ntis.gov/ordering.htm

\section{OR}

Lawrence Livermore National Laboratory

Technical Information Department's Digital Library

http: / / www.llnl.gov/tid/Library.html 


\title{
ISOTOPE EXCHANGE AND FRACTIONATION CORRECTIONS FOR EXTRACTION OF TRITIATED WATER IN SILICA GEL BY FREEZE-DRYING TECHNIQUES
}

\author{
Everett B. Guthrie, Nancy C. Shen and Bryan B. Bandong \\ Environmental Monitoring Radiological Laboratory \\ Analytical and Nuclear Chemistry Division \\ Lawrence Livermore National Laboratory \\ P.O. Box 808, L-232, Livermore, CA 94551
}

24 September 2001

\begin{abstract}
A concentration correction curve was established for measuring the activity concentration of airborne tritiated water collected with dried silica gel and extracted by the LLNL Environmental Monitoring Radiological Laboratory freeze-dry technique. A tracer study using standard tritiated water with silica gel showed that the concentration of tritium in the extracted water is lower than that in the adsorbed water by a fraction proportional to the amount of adsorbed water. The observed decrease in tritium concentration in the extracted water can be accounted for by dilution due to isotopic exchange with both nontritiated water and hydroxyl groups within the silica gel matrix. For the range of $8-35 \%$ adsorbed water, which is typical of samples collected in LLNL monitoring stations, the derived exchangeable water in the silica gel material under investigation was $(5.12 \pm 0.08) \%$. The contribution of the $\mathrm{H}_{2} \mathrm{O} / \mathrm{HTO}$ vapor pressure effect using published empirical data in the literature was also considered in calculating the degree of isotopic exchange.
\end{abstract}

\section{INTRODUCTION}

Airborne tritium in environmental atmospheric samples at Lawrence Livermore National Laboratory is monitored by collection of tritiated water (HTO) on silica gel ( $\mathrm{SiG}$ ) columns. Tracer studies have indicated that tritium concentrations measured in water desorbed from the $\mathrm{SiG}$ by techniques such as direct distillation or azeotropic distillation are consistently lower than in the original tracer solution [Patton and Cooper, 1997; Rosson et al., 2000]. Sources of the discrepancy include isotopic exchange and isotopic fractionation (vapor pressure 
isotope effect) in reducing the tritium concentration of HTO adsorbed on and then desorbed from the silica gel. The present study investigates the degree of these effects using the Environmental Monitoring Radiological Laboratory (EMRL) freezedry method.

Non-tritiated water $\left(\mathrm{H}_{2} \mathrm{O}\right)$ and hydroxyl groups $(\mathrm{OH})$ contained in the silica gel will isotopically exchange with tritium in the adsorbed tritiated water [Rosson et al., 1998]. These chemically bound moieties are retained in the silica gel even when drying at $100{ }^{\circ} \mathrm{C}$. Manufacturers of $\mathrm{SiG}$ have reported a maximum weight loss between 100 and $950{ }^{\circ} \mathrm{C}$ (the temperature when $\mathrm{SiG}$ chemically decomposes) of about $5.5-6.5 \%$, depending on the type and grade of the gel. The water and hydroxyl groups retained in the silica gel after drying, and prior to field sampling application, is herein referred to as exchangeable water. The percent exchangeable water in SiG is experimentally determined in the present report.

The isotope vapor pressure effect for HTO relative to $\mathrm{H}_{2} \mathrm{O}$ in silica gel adsorption experiments results in successively greater enrichment for HTO in the condensed phase until vaporization is taken to completion. The isotope separation factor $\alpha$ is defined as the mole fraction of $\mathrm{HTO}$ to $\mathrm{H}_{2} \mathrm{O}$ in the condensed phase; i.e. liquid phase or adsorbed in silica gel, relative to the same mole fraction in the vapor (gas) phase. Baumgartner and Kim [1990] compiled published values of $\alpha$, confirmed the values with their own measurements and developed a semi-empirical curve of $\alpha$ versus temperature that shows a decrease of $\alpha$ with increasing temperature. For the current investigation, $\alpha$ values will not be measured experimentally but will be derived from the semi-empirical function developed by Baumgartner and Kim.

\section{TREATMENT OF ISOTOPIC EXCHANGE AND FRACTIONATION}

If exchange of tritiated water with $\mathrm{H}_{2} \mathrm{O}$ and $\mathrm{OH}$ groups in the silica gel is complete, then we can express the following material balance for tritium:

amount of tritium in adsorbed water = amount of tritium in desorbed water 
This can be expressed mathematically as follows:

$$
C W=C^{\prime}(W+X)
$$

Where $C=$ initial concentration of ${ }^{3} \mathrm{H}$ in adsorbed water, e.g. in $\mathrm{pCi} / \mathrm{L}$

$C^{\prime}={ }^{3} \mathrm{H}$ concentration of desorbed water (which has been diluted with exchangeable water); e.g. in $\mathrm{pCi} / \mathrm{L}$

$X=$ fraction of exchangeable water in $\mathrm{SiG}$ before adsorption

$W=$ fraction of adsorbed water in $\mathrm{SiG}$

$=$ wet weight of $\mathrm{SiG}-$ dry weight of $\mathrm{SiG}$

dry weight of SiG

Thus the fraction of exchangeable water can be calculated by rearranging Eqn 1:

$$
X=W\left[\frac{C}{C^{\prime}}-1\right]
$$

In the preparation of tracer solutions for the present study, the tritium concentrations $C$ and $C^{\prime}$ must be corrected for isotope fractionation effects. For the "spiked" silica gel standard, the tritium tracer solution concentration $C$ adsorbed in the silica gel is lower by a factor $f_{1}$ than the concentration measured in the standard solution $C_{m}$ :

$$
f_{1}=\frac{C}{C_{m}}
$$

$C_{m}$ is the initial concentration of the standard tritium solution.

For the present investigation, the spiked SiG standards were prepared by adding known weights of $\mathrm{SiG}$ to specified amounts of frozen standard solutions of known tritium concentration. The standard solution was frozen prior to addition of the $\mathrm{SiG}$ to prevent the loss of solution via vaporization that would otherwise occur in the highly exothermic reaction between $\mathrm{SiG}$ and water at room temperature. In this manner, the preparation of the spiked SiG occurs in a controlled process and complete equilibration is attained. The other procedure for preparing the spiked 
SiG standard is by bubbling a known amount of tritium solution of known activity through a dry SiG column, and the process taken to completion by bubbling the standard solution to dryness. In either case of preparation methods of the spiked SiG standard, $f_{1}=1.0$, and thus $C=C_{m}$.

For the extraction of the adsorbed water from the SiG during the freezedrying stage, the tritium concentration in the water vapor distilled from the SiG, $C_{m}^{\prime}$, will be lower than the tritium concentration adsorbed on the silica gel, $C$, by a correction factor $f_{2}$ :

$$
f_{2}=\frac{C_{m}^{\prime}}{C^{\prime}}
$$

where $C_{m}^{\prime}$ is the tritium concentration measured in the distillate.

The value of $f_{2}$ can be derived from the following semi-empirical function developed by Baumgartner and Kim [1990]:

$$
\ln f_{2}=\frac{37813.2}{T^{2}}-\frac{136.571}{T}+0.124096
$$

where $T=$ absolute temperature; i.e. in ${ }^{\circ} \mathrm{K}$.

In the present experiment during the freeze-drying stage, the silica gel was heated to $100{ }^{\circ} \mathrm{C}\left(373{ }^{\circ} \mathrm{K}\right)$. At this temperature, Equation (5) gives $f_{2}=0.97$.

In terms of $f_{1}, f_{2}, C_{m}$ and $C_{m}$, Equation (1) may be written in the form:

$$
\left(\frac{1}{W}\right) X+1=\frac{f_{1} f_{2} C_{m}}{C_{m}^{\prime}}
$$

Note that in Equation (6), a plot of 1/W versus the factor on the right-hand side of the equation would give a linear curve with a slope $=X$ and an ordinate intercept $=$ 1. Thus, this method provides for an empirical method of obtaining the percent exchangeable water, $X$, for a given type and grade of silica gel by performing 
measurements at different percent water loading of adsorbed tritium standard solution in silica gel.

\section{PROCEDURE}

Triplicate runs at each \%-adsorbed water loading were conducted covering a range of \%-adsorbed water from $8-33 \%$. This range was selected since it encompasses the range typically obtained with actual field samples. Spiked SiG standards were prepared by adding known weights of dried SiG to known amounts of frozen tritium standard solution as discussed in the preceding section. Prior to addition of the standard tritium solution, $\mathrm{SiG}$ samples were vacuum-dried in an oven at $110{ }^{\circ} \mathrm{C}$ for 24 hours. Tritium concentrations were determined by liquid scintillation analysis counting the samples for a period of time to meet a preset 2sigma counting error of $2 \%$ at the $95 \%$ confidence level.

Freeze drying was carried for at least 3 days. As had been mentioned above, the SiG samples were heated to $100{ }^{\circ} \mathrm{C}$ in a heating mantle during the freeze-drying stage. Seven-and-half (7.5) $\mathrm{mL}$ aliquots of the distillate were collected and counted in a liquid scintillation analyzer.

\section{RESULTS}

Measurements of tritiated water tracer adsorbed on the silica gel are presented in Table I. Using the data of Table I, the plot of Equation (6) is provided in Figure 1. The derived value for the percent exchangeable water (\%), $X$, is $5.12 \pm$ 0.08. By comparison, other values reported in the literature are:

\footnotetext{
Present Study (freeze-dry) $5.12 \pm 0.08$

Rosson et al, 1998 (azeotropic distillation) $5.9 \pm 0.7$

Rosson et al, 2000 (direct distillation) $6.3 \pm 0.5$

Fox, 1998 (azeotropic distillation) $5.3 \pm 0.2$

Hudson, 2001 (He Mass Spectrometry 5.8 single measurement only)
} 
Relatively good agreement can be seen among the reported values.

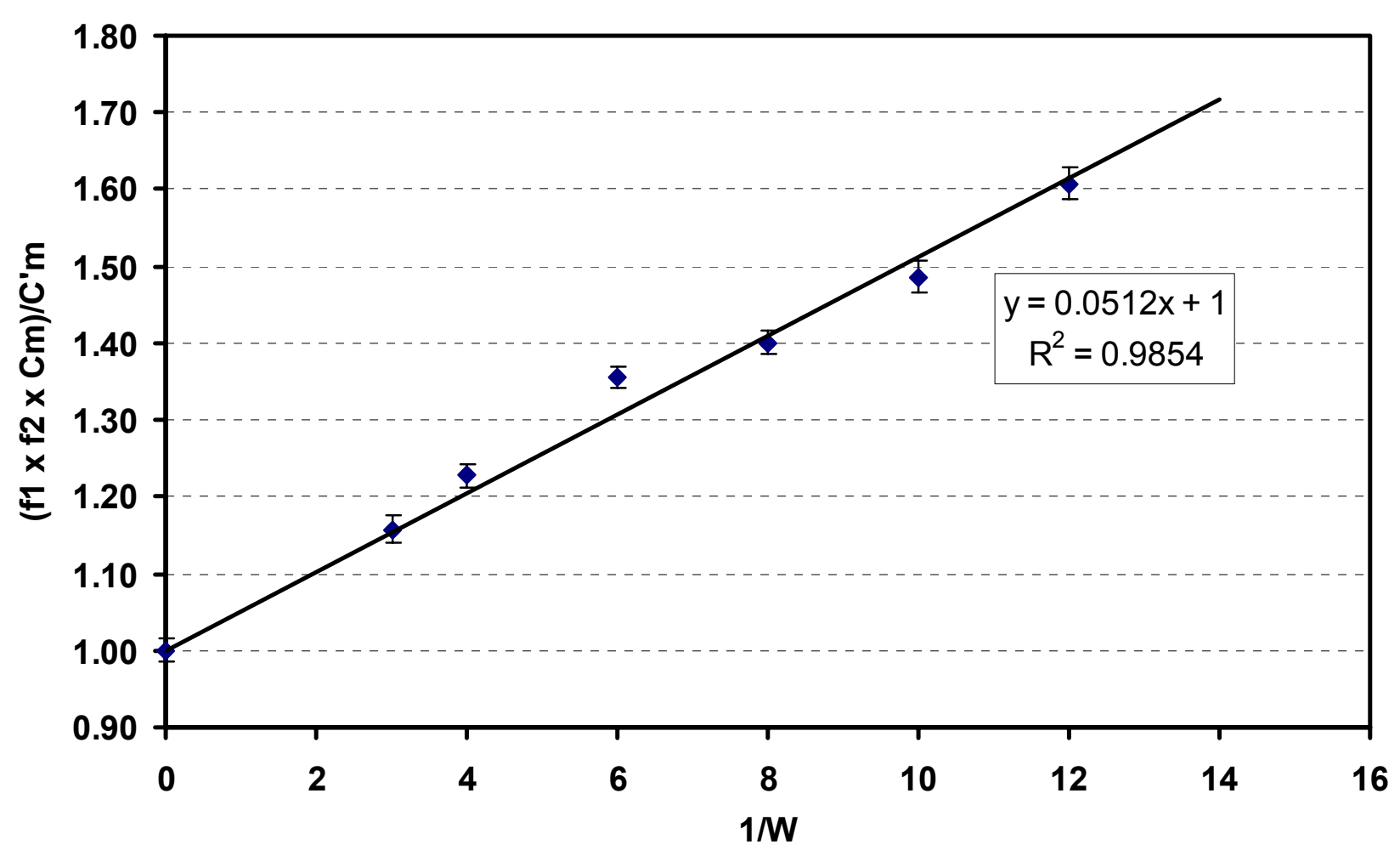

Figure 1. Derivation of the \% exchangeable water, $X$, using the technique of Equation (6). 
Table I. Measurements of tritiated water tracer solution adsorbed on silica gel columns and extracted by freeze-dry method.

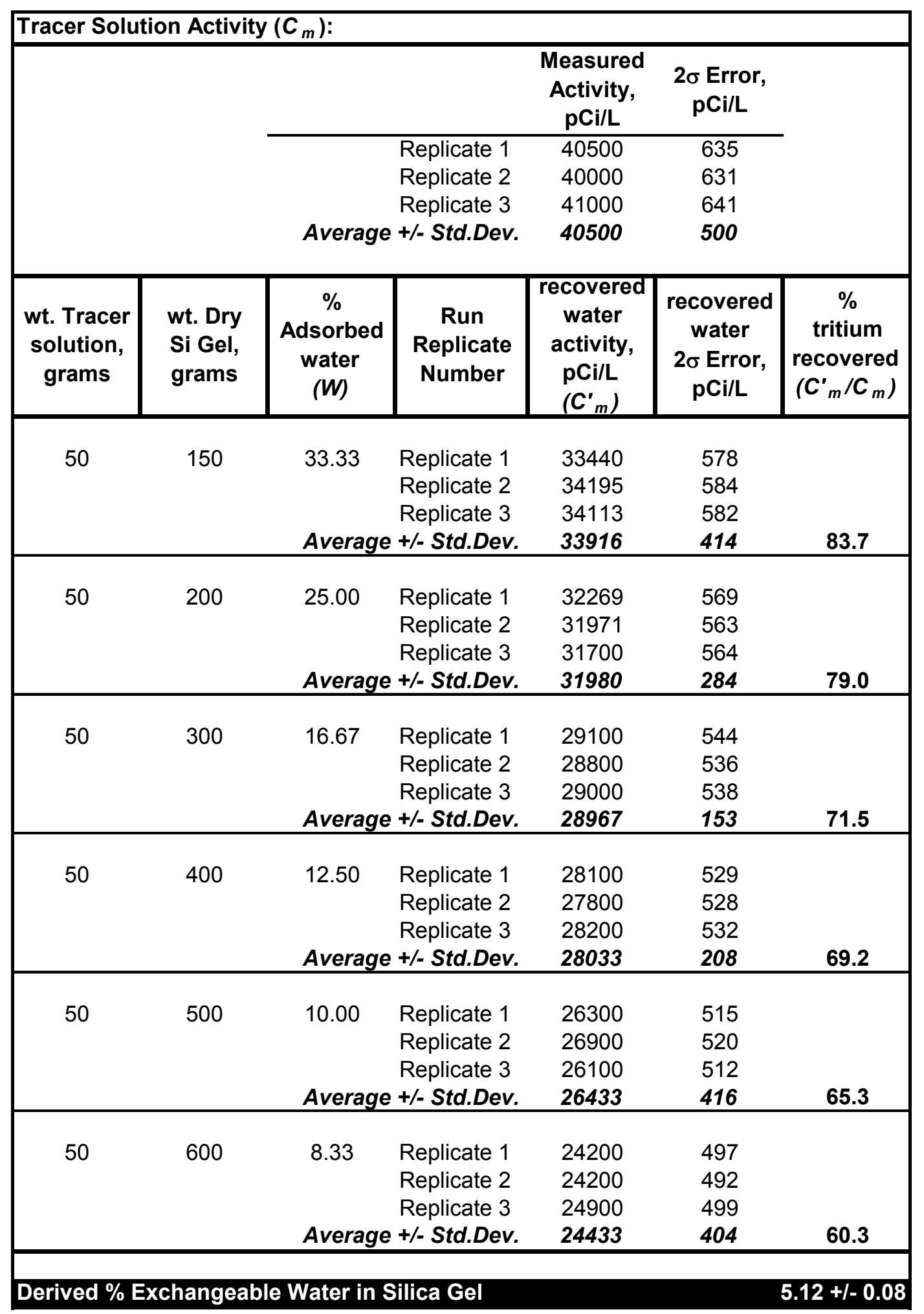


CORRECTING EMRL DATA FOR ISOTOPIC EXCHANGE AND

FRACTIONATION USING THE ABOVE DATA

Equation (1) can be rewritten as follows:

$$
\frac{C}{C^{\prime}}=\frac{X+W}{W}
$$

or expressing $C$ and $C^{\prime}$ in terms of measurable values,

$$
\frac{C}{C_{m}^{\prime}}=\frac{1}{f_{2}}\left[\frac{X+W}{W}\right]
$$

and substituting for $X$ and $f_{2}$,

$$
C=1.0309\left(C_{m}^{\prime}\right)\left[\frac{0.0512+W}{W}\right]
$$

Equation (9) can be used to correct the measured concentration $C_{m}^{\prime}$ given the fraction of adsorbed water $W$. This function is depicted graphically in Figure 2.

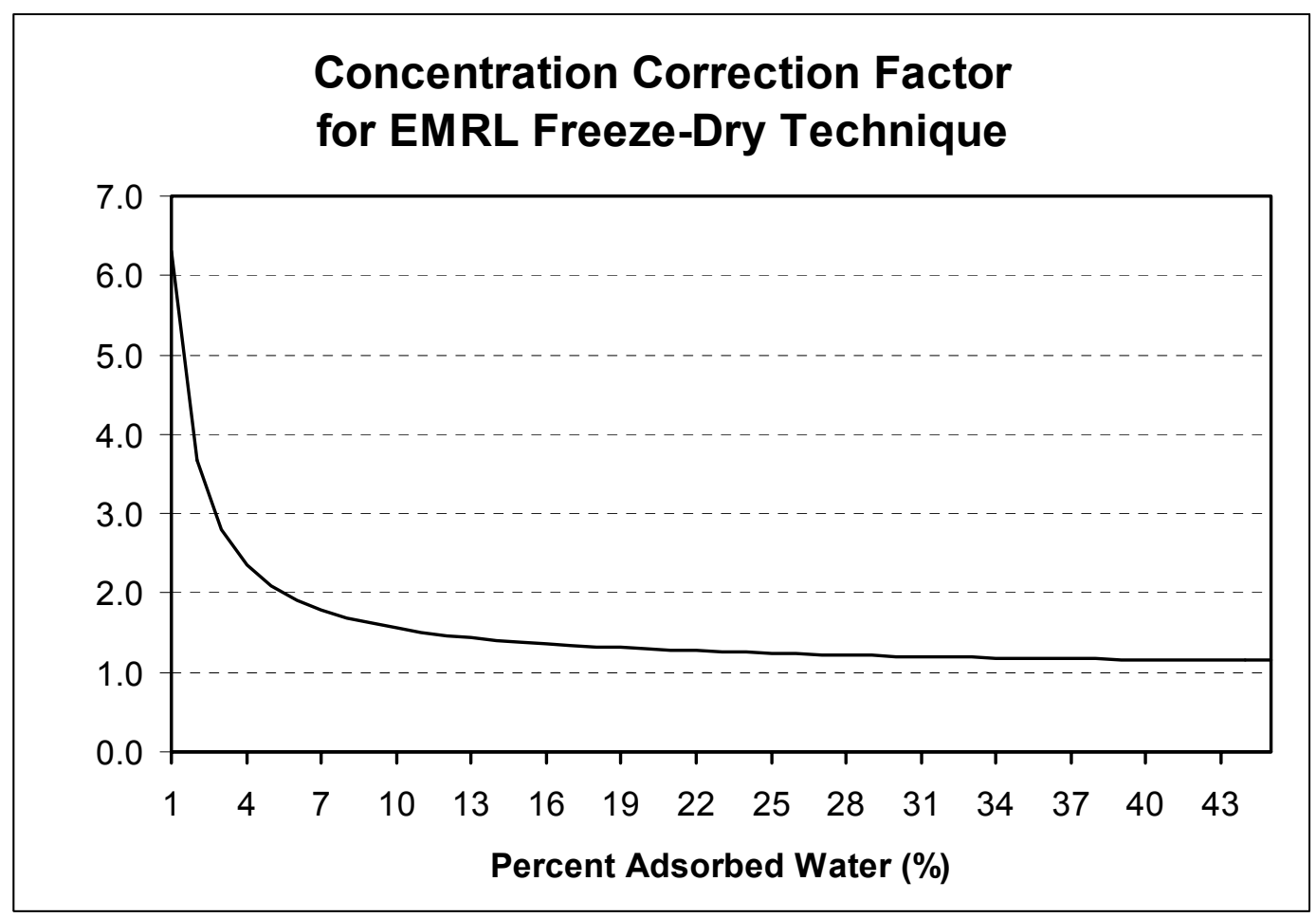

Figure 2. Concentration correction factor for HTO collected in SiG and measured by EMRL freeze-dry method. 
As demonstration of the application of Equation (9), Table II exhibits correction factor for selected water loading (\% adsorbed water). For example, for a $10 \%$ adsorbed water, the correction factor is 1.559 . Thus to obtain the true tritium concentration in the adsorbed water (and hence the true airborne concentration collected in the silica gel), the measured tritium activity $C_{m}^{\prime}$ in the distillate from the freeze-drying process is multiplied by 1.559 ; i.e. $C=1.559_{\mathrm{X}} C_{\mathrm{m}}$. This means that a correction of $55.9 \%$ needs to be applied to the measured tritium actvity.

Table II. Airborne tritium activity correction factors as a function of the percent adsorbed water in the silica gel.

\begin{tabular}{|c|c|}
\hline $\begin{array}{c}\% \\
\text { Adsorbed } \\
\text { Water }\end{array}$ & $\begin{array}{c}\text { Correction } \\
\text { Factor } \\
\left(C / C^{\prime} m\right)\end{array}$ \\
\hline 1 & 6.309 \\
\hline 5 & 2.087 \\
\hline 10 & 1.559 \\
\hline 15 & 1.383 \\
\hline 20 & 1.295 \\
\hline 25 & 1.242 \\
\hline 30 & 1.207 \\
\hline 35 & 1.182 \\
\hline 40 & 1.163 \\
\hline 45 & 1.148 \\
\hline 50 & 1.136 \\
\hline
\end{tabular}

\section{REFERENCES}

Fox, R., 1998, LBNL private communication.

Baumgartner, F. and M. A. Kim, 1990, Appl. Radiat. Isot. 41:395.

Hudson, 2001, LLNL private communication.

Patton, G. W. and A. T. Cooper, 1997, Health Phys. 72:397.

Rosson, R., R. Jakiel and B. Kahn, 1998, J. Phys. Chem. 102:10342.

Rosson, R., R. Jakiel, S. Klima, B. Kahn and P. Fledderman, 2000, Health Phys. 78: 68. 
Acknowledgement: This document was prepared as an account of work sponsored by an agency of the United States Government. This work was performed under the auspices of the U.S. Department of Energy by Lawrence Livermore National Laboratory under Contract W-7405-ENG-48. N/1367. 